\title{
SCLERODERMA AND MELORHEOSTOSIS
}

\section{Report of a Case}

\author{
N. M. Thompson, C. E. L. Allex, G. S. ANidrews \\ and F. N. (illlwald), Derbax, Solth Africa
}

From the King Edward IIII Hospital, Iurban

An Indian girl aged ten years complained of pain in the knee and a bad limp due to deformity of the right leg. This deformity had been present since birth, but had become steadily worse with growth. Pain was not very severe. In the family history there was no record of any similar condition.

Clinical examination-Apart from the findings referable to the right leg, there was no important abnormality. The patient exhibited the old scarring of an infected scabies commonly found among this class of patient.

The child walked with a marked limp, keeping the right knee flexed about 30 degrees, the tibia being medially rotated about 20 degrees on the femur (Fig. 1). In addition to the

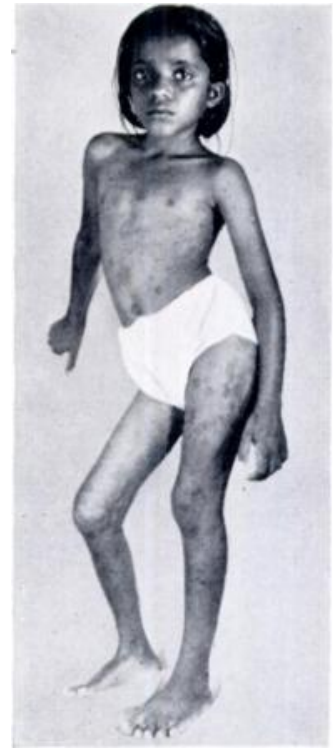

Iili. 1

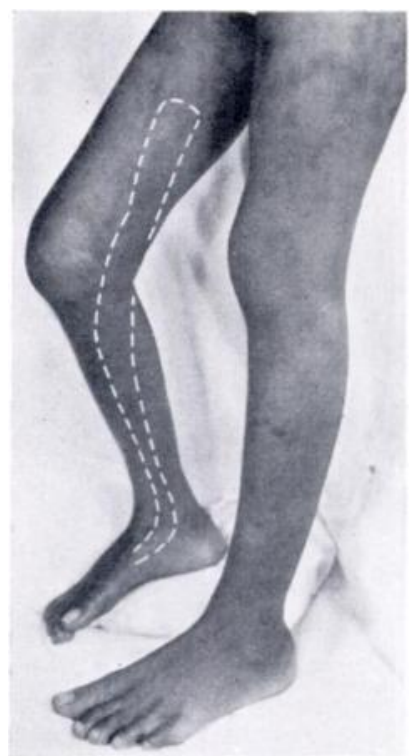

Fici. 2

Figure 1-l'atient at the age of ten years. Niste flexionadduction contractures of knee, ankle and foot. Figure 2The affected area of skin has been marked out; changes of texture are just discernible in the photograph.

flexion and medial rotation deformity there appeared to be some real genu varum. The foot was drawn into varus, and the child walked on the outer border of the foot, but without any equinus (l丷ig. :2).

Hip movements were full. The right knee could be flexed to 90 degrees; extension was 20 degrees short of full. At the ankle joint, dorsiflexion was full but plantar flexion was to a right angle only. Inversion-adduction at the tarsus was full; eversion-abduction was to just less than the neutral position. 
There was a linear scleroderma, extending from the thigh downwards, which overlaid and appeared to involve the sartorius, tibialis anterior and abductor hallucis muscles (Fig. $\mathbf{2}$ ). The fibrous thickening extended from the upper thigh downwards. The skin was bound by fibrous strands to the underlying muscle. Over the area where the sartorius expands round the postero-medial aspect of the knee joint towards its insertion there was gross thickening of the skin and subcutaneous tissue and the patella was anchored and displaced medially from its normal position. There was one and a half inches shortening of the femur, and one inch shortening of the tibia. Blood Wassermann reaction was negative.

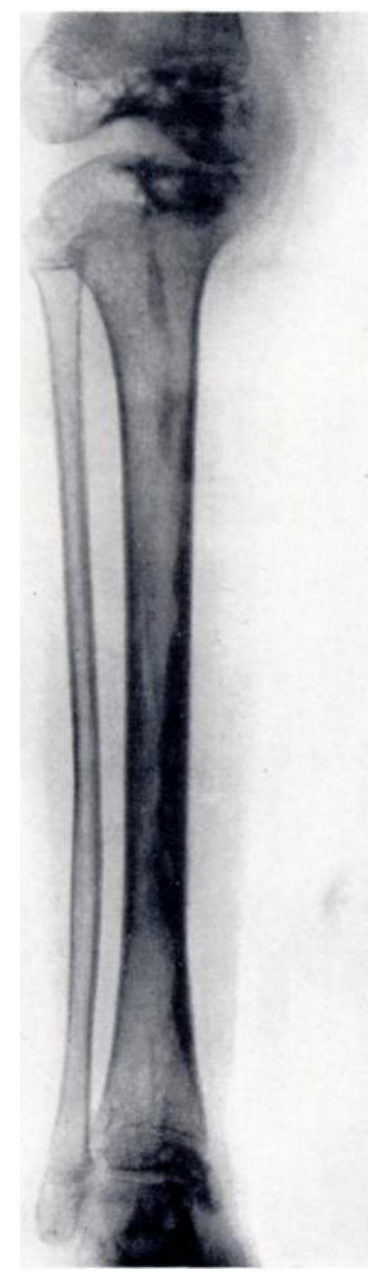

FIG. 3

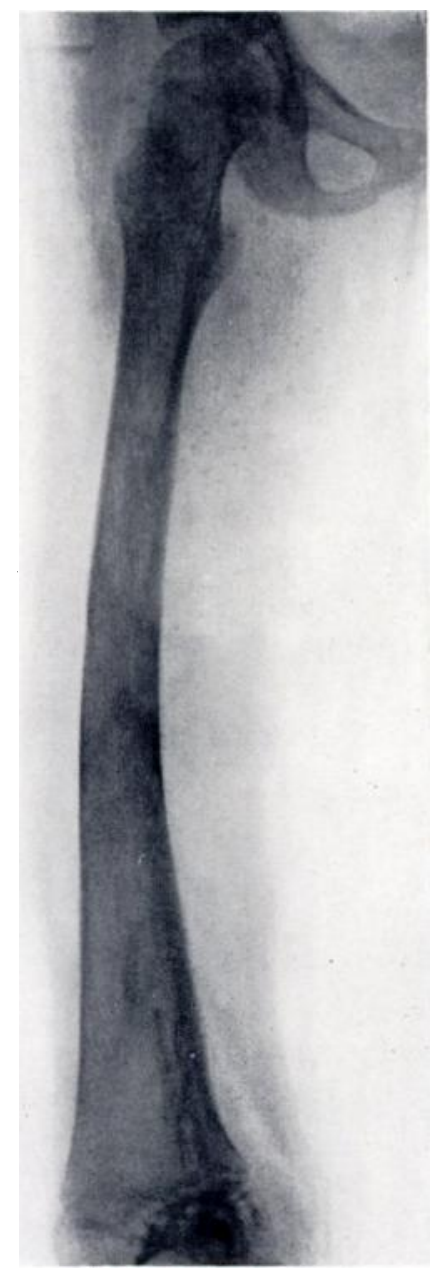

FIG. 4

Figure 3-Right knee joint and tibia. Note "flow" of dense bone at medial aspect of tibial shaft, and epiphysial changes confined to the medial half of each bone. The talus is also affected. Figure 4--Right femur. The changes are less well marked than in the tibia and affect mainly the lower half of the shaft.

It was considered that the abnormal fibrous tissue was responsible for the deformity, and that it might have caused retardation of growth at the medial side of the epiphysial plates.

Radiographic examination. Right tibia--The medial aspect of the shaft showed irregular cortical thickening, most marked in the middle third where the appearance suggested a "flow" of dense bone (Fig. 3). Both tibial epiphyses, the distal femoral epiphysis and the patella showed irregular densities forming a somewhat coarse lace-work appearance. All the 
changes were confined to the medial side. Right femur-The distal epiphysis showed changes similar to those found in the other epiphyses; they were confined to the medial half. The shaft of the femur showed a "flow" of bone on its medial aspect and most marked in the

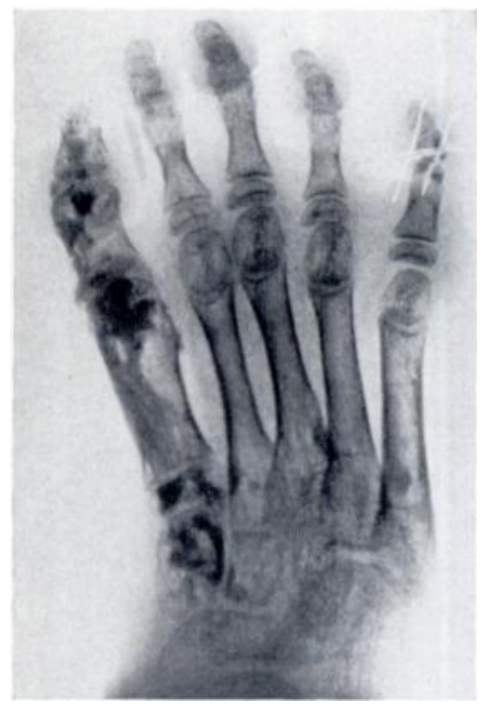

Fici. 5

Right foot, showing involvement of all the bones at the medial border of the foot, distal half (Fig 4). The changes were less marked than those in the tibia. Right foot-The talus, navicular, medial cuneiform, first metatarsal and the two phalanges of the hallux were affected (Fig. 5). The shafts of the metatarsal and phalanges showed changes like those seen in the tibial shaft; the changes in the tarsal bones were mostly endosteal and represented by splashes and dots. Involvement of the navicular was minimal. Very slight changes represented by cortical thickening at the bases of the other metatarsals were observed. Left foot--Changes of an osteopoikilic nature were present in the phalanges of the left foot. Peli'is-Minimal changes were observed in the right acetabulum. Other bones-A suggestion of osteopoikilic changes was noted in the carpal bones and in the distal radial epiphyses, especially on the right side (Fig. (6). The skull, spine and thoracic cage appeared normal.

Operation 1 curved incision was made from the midthigh along the line of the sartorius to its insertion. The skin was between an eighth and a quarter of an inch thick, and on its subcutaneous aspect the fat was interlaced by dense strands of fibrous tissue. The sartorius muscle was missing, its place being occupied by thick yellow fibro-fatty tissue. The part of adductor longus which normally is attached to the adductor tubercle was missing, as was the distal third of the gracilis. All the fibro-fatty tissue was excised; it cut "grittily" like a green pear. The capsule of the knee joint was incised medially to release the patella. The deformity of the knee was thereby corrected. After operation the limb was immobilised in plaster.

The child died four dars after operation; death was attributed to fat embolism. Consent for autopsy was refused.

Histological examination (of specimens excised at operation). Skin-There were slight hyperkeratosis, thinning of the epidermis and dense fibrosis of the corium. Muscle tissuc - Sections showed scattered degenerated voluntary muscle fibres and "replacement" by fatty tissue. Bone (from upper part of tibia)-The specimen consisted of dense compact living bone.

\section{DISCUSSION}

In 1922 Leri and Joanny reported a type of bone pathology to which they applied the name of melorheostosis, or flowing hyperostosis of a limb. Putti (1927) described two cases, each with a lower limb affected, under the title "osteosis eburnisans monomelica."

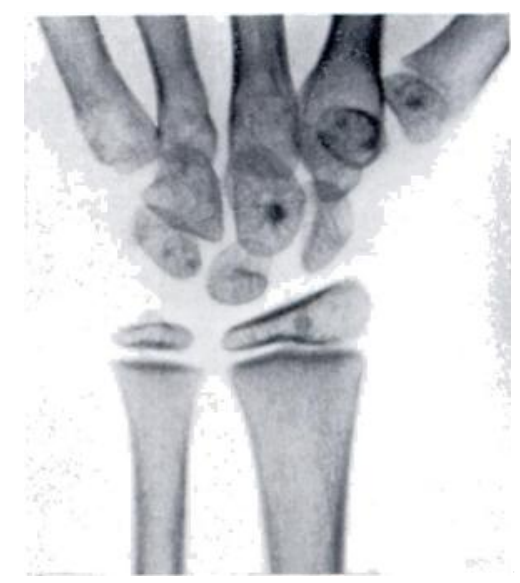

FIG. 6

Right carpus. Most of the carpal bones show stippling suggestive of osteopoikilosis.

Dillehunt and Chuinard (1936) reported a case in which scleroderma was superimposed upon the area affected in the bone. Up to that date nineteen cases had been described. This total has since been increased to over forty, but Fairbank (1948) stated that only four unquestionable 
cases have been described in the United Kingdom (Wakeley 1931, Boggon 1938, Franklin and Matheson 1942, Le Vay 1946). Hess and Street (1950) reported a case in which pain, the predominant symptom, was treated by sympathectomy with encouraging results.

The most striking features of the case described here were linear scleroderma and contraction deformity. Pain was not severe, although it is reported by others to be the most frequent symptom. The radiological findings were characteristic, although accompanied in a minor degree by changes of an osteopoikilic type. No evidence of involvement of the skull, spine or ribs was present. Histological examination of the excised specimens of skin, muscle and bone was not very helpful. In Hall's case (1943) there were thickening of the skin and fibrosis of underlying tissues; the bone was highly vascular and the periosteum lost in a feltwork of overlying fibrous tissue undergoing bony invasion. Histological reports are apparently somewhat conflicting, but they indicate that dense areas are the seat of sclerosis, with lamellae arranged in a bizarre manner. Concentric perivascular ossification is sometimes mentioned.

Of interest in this case was the way in which the undifferentiated fibroblastic tissue involved all structures from the deeper skin layers down to, and including, the bone. This observation suggests strongly that a primary mesoblastic defect arises in a part of the limb bud before its development into a rotated and definitive limb; there is possibly a disturbance of cell potential in the somatopleural mesoderm. Zimmer (1927) suggested a developmental error, the result of embryonic metameric disturbance.

The death of our patient from fat embolism made it impossible to confirm or deny the observations of Leri and Joanny (1922), who considered that the condition was progressive, as it proved in their original case. Progression of the deformity in our case was ascribed to continued normal epiphysial bone growth with unresponsive bowstringing of the soft tissues. Correction of the soft tissue abnormalities was all that was required to overcome the deformity. Although radiographic findings have been stressed in the literature, it is possible that much more emphasis should be laid on the abnormality of the soft tissues.

Our thanks are accorded to Dr J. Parker, Superintendent of King Edward VIII Hospital, for permission to submit this case for publication, and to Dr J. Wainwright for the histological report.

\section{REFERENCES}

Boggon, R. H. (1938): Proceedings of the Royal Society of Medicine (Clinical Section 29), 32, 439.

Dillehcst, R. B., and Chuinard, E. G. (1936): Journal of Bone and Joint Surgery, 18, 991

Fairbaik, H. A. T. (1948): Journal of Bone and Joint Surgery, 30-B, 533.

Franklin, E. L., and Matheson, I. (1942): British Journal of Radiology, 15, 185.

HALL, G. S. (1943): Quarterly Journal of Medicine, N.S. 12, 77.

Hess, W. E., and Street, D. II. (1950): The Journal of Bone and Joint Surgery, 32-A, 422.

Leri, A., and Joanny, J. (1922): Bulletins et Mémoires de la Société Médicale des Hôpitaux de Paris, 46, 1141.

LE VAY, A. D. (1946): British Journal of Surgery, 34, 211.

Putri, V. (1927): Chirurgia degli Organi di Movimento, 11, 335.

Wakeley, C. P. G. (1931): Proceedings of the Royal Society of Medicine (Clinical Section 17), $25,145$.

ZiMMER, P. (1927): Beiträge zür klinischen Chirurgie, 140, 75. 